
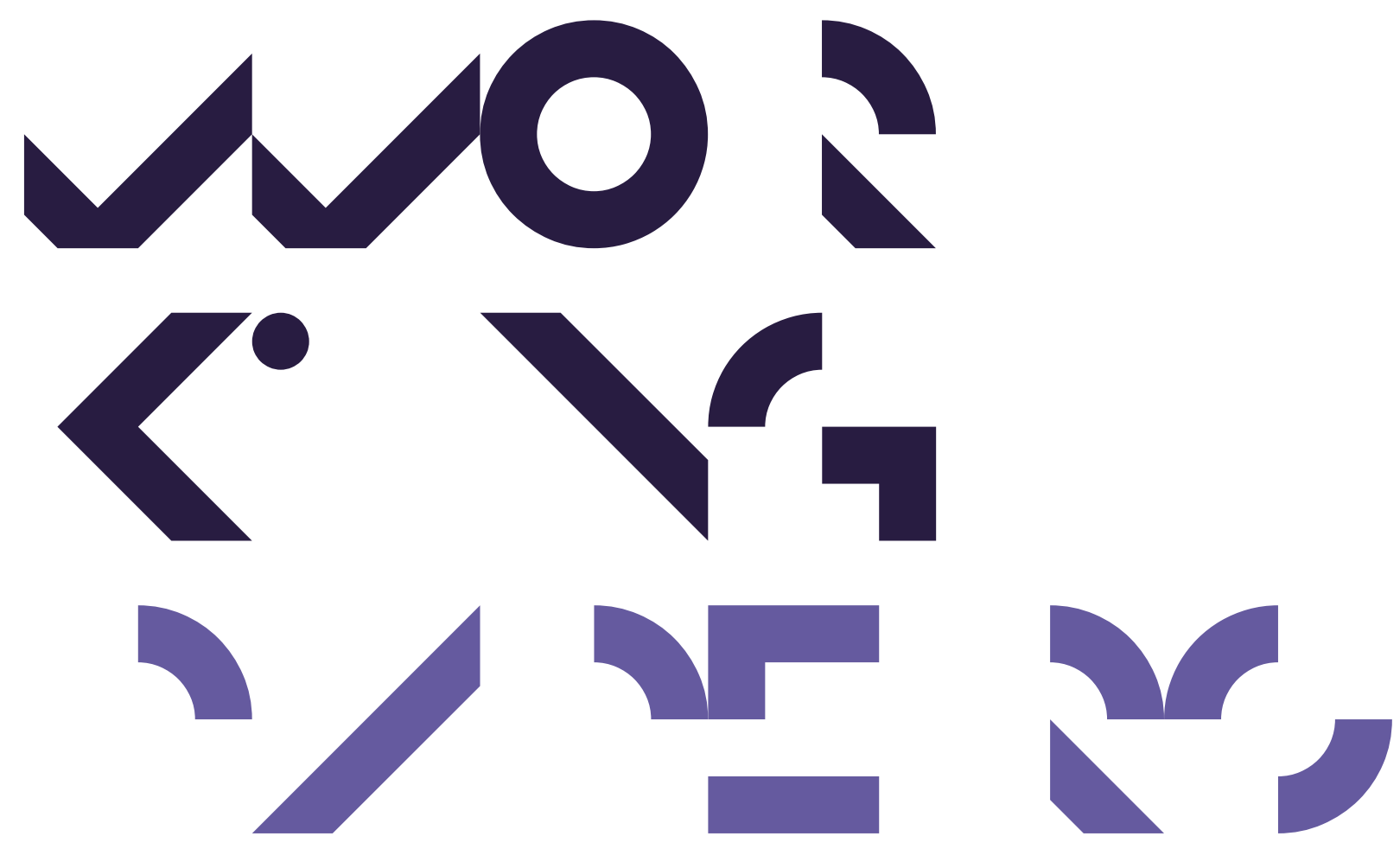

Economics Working Papers

2015-17

Heterogeneous Impacts on Earnings from an Early Effort in Labor Market Programs

Kenneth Lykke Sørensen

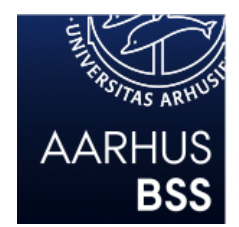




\title{
Heterogeneous Impacts on Earnings from an Early Effort in Labor Market Programs*
}

\author{
Kenneth Lykke Sørensen \\ Aarhus University
}

September 1, 2015

\begin{abstract}
Labor market programs that are found to shorten unemployment duration might not be societal efficient if participants do not find suitable jobs in terms of stability, wages, occupation, etc. This paper investigates whether a program, that previously has been shown to lower unemployment duration, also had positive effects on jobs with respect to labor market earnings. The contribution of the paper is two-fold: First, we show that the program had positive effects on earnings in the short term for men, and in the medium and long term for men in one county, which we attribute to the mere taxing of leisure time and human capital accumulation/removal of frictions, respectively. Second, we show that the positive effects are heterogenous across earnings distributions. Taxing leisure time primarily affects low earners while human capital accumulation and removing frictions tend to help high earners.
\end{abstract}

JEL codes: J31, J64, J68

Keywords: Active Labor Market Policies, randomized controlled trial, quantiles, earnings.

${ }^{*}$ Department of Economics and Business, Aarhus University, Fuglesangs Allé 4, DK-8210 Aarhus V, Denmark, ksoerensen@econ.au.dk. I wish to thank Lars Skipper, Knut Røed, Anders Forslund, Dario Pozzoli, Bernd Fitzenberger, and especially Jeffrey Smith for valuable comments and suggestions. Additionally, I thank participants at the annual CAFÉ workshop, Vejle Denmark 2014, the Nordic Summer Institute in Labor Economics, Helsinki Finland 2014, the Nordic Workshop on Register Data and Economic Modeling, Oslo Norway 2015, the 29th Annual Conference of the European Society for Population Economics, Izmir Turkey 2015, and the fourth SOLE|EALE World Meetings, Montreal Canada 2015 for comments and suggestions. I also thank the Cycles, Adjustment, and Policy research unit, CAP, Department of Economics and Business, Aarhus University sponsored by the Danish National Research Foundation for support and for providing the data. Finally, I greatly acknowledge financial support from the Danish Council for Independent Research | Social Sciences (grant no. FSE 4182-00281). 


\section{INTRODUCTION}

Many welfare states are characterized by a flexible labor market for firms and a generous social safety net for redundant workers. They typically entail a large public sector, high social benefits, low firing costs and are sustainable under two conditions: (i) that the unemployment rate is low and (ii) that the labor market participation rate is high. Due to the presence of frictions and a depreciation of human capital, those welfare systems provide a wide range of Active Labor Market Programs (ALMP) to ease the transition of laid off workers out of unemployment. Since the usage of ALMPs by now is the norm, it is no longer the question of should we make use of labor market training, but rather which kind of training, and which timing should the programs have, that are key questions. This paper sheds light on the latter by examining whether advancing ALMP to early in the unemployment spell has short term and/or long term consequences on earnings and if they affect different workers differently.

Active labor market programs are generally intended to operate in two dimensions: (i) reduce frictions and rebuild human capital of the unemployed worker, and (ii) induce the unemployed to search actively for a job. We find evidence suggesting that advancing ALMP to the early stages of an unemployment spell drives the former in one sample and the latter, in terms of taxing of leisure time, in the other three of our four samples.

The Public Employment Services (PES) should organize contacts with the unemployed workers in such a way that those in need of updated skills are given training and those already capable of taking up a job are taught how to search for the right jobs. However, due to institutional constraints and lack of complete knowledge of ALMP systems it is difficult in practice to set up a system that works efficiently in terms of costs, unemployment duration, employment outcomes, etc. This paper contributes to the knowledge by examining the effects of an early intervention towards newly unemployed workers on earnings. The early intervention includes (in this sequence): job search assistance, meetings with a case worker, and formal labor market training. Instead of focusing on exit to employment or not, we make use of detailed data and inspect earnings in the short, medium, and long term from early participation in active labor market policy programs. ${ }^{1}$ To do this, we

\footnotetext{
${ }^{1}$ Following the definition of Card, Kluve, and Weber (2010, 2015), earnings one to four quarters, five to eight quarters and nine to eleven quarters after entering the RCT relate to short, medium, and long term outcomes, respectively.
} 
explore a randomized controlled trial (RCT) carried out during the winter of 2005/2006. The purpose of the RCT was to test whether an early effort could help newly unemployed workers back to work faster than otherwise. All workers entering a fresh unemployment spell during the trial window participated in the trial which lasted for up to 39 weeks into the unemployment spell. Random assignment by day of birth allocated roughly half of these individuals to a treatment group with early ALMP participation and half to a control group who stayed in the ongoing system where they only needed to meet with a case worker every 13 weeks. We use Danish administrative register data that allow us to measure labor market careers of all individuals involved in the RCT, both prior to entering the RCT and up to eleven quarters after. From these registers, we construct average quarterly earnings by following each of their employment spells. Our findings suggest that the early effort primarily affects average earnings in the short term, and using a quantile approach we show a heterogeneous impact where low earners respond more towards the intervention than medium to high earners. The early intervention places more requirements upon the unemployed in the sense that they actually had to meet at the PES and thus spend time that would otherwise be left for themselves and thereby taxed the leisure time for the treated compared to the non-treated.

Since ALMP schemes are designed to both increase the exit rate out of unemployment and to provide the unemployed with better skills in order to improve the quality of the worker-firm match, it is thus not sufficient to only evaluate exit and return rates but also take into account post-unemployment labor market outcomes (see Crepon, Dejemeppe, and Gurgand (2005)). Previous studies have hence examined earnings gains/losses from no versus some labor market training. ${ }^{2}$ Munch and Skipper (2008) e.g. examine how ALMP participation between 1995-2000 affects transition to employment and wages on Danish data. They find that labor market training lowers hourly wages but prolongs the duration of employment. They also highlight the importance of including labor market outcomes as the measure of evaluating ALMP settings. To further increase our understanding of ALMP impacts on post-unemployment employment, this paper focuses on a very important outcome, i.e. earnings. However, this paper differs from such analyses by investigating advanced treatment versus normal treatment and thus complements these papers. Often treatment effects are identified by assuming proportionality between

\footnotetext{
${ }^{2}$ See e.g. Lechner (1999), Larsson (2003), Black, Smith, Berger, and Noel (2003), Jespersen, Munch, and Skipper (2008), and Gaure, Røed, and Westlie (2012).
} 
elapsed duration (baseline hazards) and a regressor function as well as a finite distribution of unobserved heterogeneity ensuing that a mixed proportional hazard framework can be applied (see Abbring and van den Berg (2003)). Other frameworks, labeled matching methods, identify treatment effects by assuming that observable variables describe all relevant mechanisms behind selection into programs and subsequent labor market outcomes (see Heckman, Ichimura, and Todd (1997a)). By using a randomized controlled trial we effectively identify treatment impacts directly without the usual assumptions and parametric restrictions. However, as we point out later, we do weight our estimates by inverse propensity scores, although this only slightly affects the results.

Using propensity score matching, Lechner (1999) finds no positive effects of off-the-job training on earnings or employment probabilities for East German workers after the unification. Using a similar approach Jespersen et al. (2008) analyze costs and benefits of labor market programs in Denmark. They find both public and especially private job training to have positive earnings effects, even after correcting for the opportunity costs of training. However, their analysis relates to effects from training versus no training (or training at a later point in time). For two Swedish labor market programs targeted towards young unemployed, Larsson (2003) finds zero or negative short term effects and zero or slightly positive long term effects of participating in the programs. Instead, in the duration literature, Gaure et al. (2012) examine effects of unemployment benefits and ALMP participation on unemployment duration together with short term post-unemployment employment stability and earnings in Norway. They find that participation in ALMP lengthens the unemployment duration. However, they estimate ALMP to induce a higher probability of eventually finding a job, and once the job is found, expected earnings have increased as well. Examining young workers staying unemployed for more than nine months after finishing school, Cockx and Picchio (2013) find that prolonging the unemployment lowers the chance of getting a job, but has no effect on starting wages once a job is found. Of course, when analyzing non-experimental data, authors need to impose strict assumptions on their models in order to identify causal effects of treatment. Instead, when clearly defined experiments are available, less stringent assumptions deliver causal effects. For a US ALMP experiment, targeted unemployed believed to have a low probability of re-entering employment before benefit exhaustion, Black et al. (2003) find that program participation decreases expected unemployment by 2.2 weeks with subsequent earnings increased by 
$\$ 1,000$.

However, these papers all deliver average impacts. ${ }^{3}$ Heckman, Smith, and Clements (1997b) were among the first to acknowledge that average program effects cannot always constitute an adequate measure of total welfare gains from treatment and instead showed how to use a quantile approach to identify heterogeneous treatment effects. Bitler, Gelbach, and Hoynes (2006) also showed that although average effects deliver interesting insights, they might cover clear heterogeneous effects over earnings distributions. Often specific treatments given on a broad scale to all unemployed unrelated to their position in the earnings distribution might affect different types differently. Comparing two experimental programs - one disregarding income from tax up to the poverty line and the other disregarding income up to a fixed, but lower threshold - they find considerable heterogeneous impacts conditional on the earnings distribution. This paper fits into the growing literature estimating heterogeneous impacts instead of average impacts of labor market programs. Djebbari and Smith (2008) find strong heterogeneous impacts (by subgroups) of the Mexican conditional cash transfer program PROGRESA. Using the same model as Djebbari and Smith (2008), Bitler, Gelbach, and Hoynes (2008) examine varying effects of workplace injuries on earnings and Dammert (2009) explores quantile treatment effects of a conditional cash transfer program in Nicaragua.

The rest of this paper is laid out as follows: Section 2 sketches our data and the institutional setting. Section 3 discusses which effects are ex ante expected of the RCT, section 4 reviews the econometric methodology that we utilize, and in section 5 we present our empirical results. Finally, section 6 concludes.

\section{Data And Institutional Settings}

The Danish labor market is characterized by a flexible hiring/firing procedure and a generous benefit system. This system can only be maintained by securing that workers who are laid off search actively for new jobs and if necessary, build upon their human capital. Over the years the Danish labor market has seen a considerable number of reforms that have entailed more and more requirements of the unemployed workers in order to keep their rights to UI benefits. Alongside with the system becoming more advanced there has also been a growing interest from the Danish government in expanding the knowledge on

\footnotetext{
${ }^{3}$ Black et al. (2003) estimate heterogeneous impacts in an earlier working paper version, though.
} 
TABle 1: UnEMPlOyMENT RATES IN PERCENT.

\begin{tabular}{|c|c|c|c|c|c|}
\hline & 2004 & 2005 & 2006 & 2007 & 2008 \\
\hline Denmark & 5.8 & 5.1 & 3.9 & 2.7 & 1.9 \\
\hline West and South Zeeland ${ }^{\diamond}$ & 6.0 & 5.2 & 3.9 & 2.9 & 2.0 \\
\hline Southern Jutland & 5.3 & 4.6 & 3.1 & 2.0 & 1.3 \\
\hline \multicolumn{6}{|l|}{ Men } \\
\hline Denmark & 5.4 & 4.5 & 3.3 & 2.3 & 1.8 \\
\hline West and South Zeeland ${ }^{\diamond}$ & 5.4 & 4.5 & 3.2 & 2.3 & 1.9 \\
\hline Southern Jutland & 4.5 & 3.7 & 2.4 & 1.6 & 1.2 \\
\hline \multicolumn{6}{|l|}{ Women } \\
\hline Denmark & 6.3 & 5.7 & 4.5 & 3.2 & 2.0 \\
\hline West and South Zeeland ${ }^{\diamond}$ & 6.6 & 5.9 & 4.7 & 3.5 & 2.1 \\
\hline Southern Jutland & 6.4 & 5.6 & 4.0 & 2.6 & 1.5 \\
\hline
\end{tabular}

what are the most successful programs in terms of bringing back the unemployed to employment. Several countries have initiated randomized control trials to investigate causal effects of labor market programs, and after the turn of the millenium, Denmark joined the list.

When the RCT used in this paper was initiated during 2005, the Danish unemployment rate started to decline after a rising trend since 2000. However, it was still difficult to foresee whether this was a temporary rebound or a longer term decrease in unemployment. The worker entering unemployment in 2005/2006 had to register as unemployed at the local PES to be eligible for UI benefits. Next, he needed to participate in a basic registration meeting within the first four weeks of unemployment and then to participate in an interview with a case worker every thirteen weeks. Finally, he would be enlisted into a labor market program after six months, if aged below 30 or above 60, or after 12 months otherwise. Thus there were not many time-consuming activities for newly unemployed workers during the first 6-12 months of their unemployment spell. ${ }^{4}$ The National Labor Market Board wished to examine whether this system could be improved by forcing newly unemployed into a more intense scheme during the first 30 weeks of unemployment. This led the National Labor Market Board to recruit counties for the first big RCT regarding active labor market programs to be conducted in Denmark during the winter of 2005/2006 entitled Quickly Back to Work (henceforth denoted QB). Two counties - Southern Jutland and Storstroem - volunteered to take on the responsibilities of carrying out the QB program.

Since both Southern Jutland and Storstroem county volunteered to carry out QB, they needed to find extra ressources that could be put into maintaining the current labor

\footnotetext{
${ }^{4}$ The maximum period of receiving unemployment insurance benefits was four years.
} 
market system for the control group as well as for all unemployed workers who were not put into the RCT (those that were not newly unemployed). To ensure that treating the treated did not crowd out either the control group or the other unemployed workers, both counties were compensated with extra person-hours.

Geographically, Southern Jutland and Storstroem are both counties without larger cities and lie in the geographically outer regions of Denmark. ${ }^{5}$ Table 1 shows that West and South Zealand (which cover Storstroem county) saw slightly higher unemployment rates than the Danish average after 2004, while Southern Jutland had lower unemployment rates than Denmark on average from 2004 to 2008. In both counties as for Denmark, there was a lower unemployment rate among men than women. Table 1 also indicates that pooling the counties together should be done carefully, as they could constitute two different labor markets. Southern Jutland participants faced a lower local unemployment rate than their Storstroem counterparts and an assumption that treated and non-treated in one county had the same employment possibilities as in the other could very easily be violated. These facts, on top of slight differences in the RCT structure between the counties are the reasons that we will not be pooling the counties together, but instead do the full analysis on each county separately for men as well as women.

A primary county difference in the economic setting during the trial was obviously the local unemployment rates (cf. Table 1). Nonetheless, unemployment in both counties was still at relatively low rates during the trial, and it is plausible that they will not be the driving force behind our results, and at the least both treated and non-treated within counties faced the same local labor market. Of course, the unemployment rate is only showing one side of the state of the labor market that the unemployed workers are situated in. If e.g. there are no open jobs for the unemployed to apply for, then a low unemployment rate will not indicate easy access to employment. The term of labor market tightness (the ratio of vacant jobs to unemployed workers) reveals how many open positions per unemployed are available and gives a broader picture of the state of the labor market. Table 2 shows the labor market tightness for the two counties. In 2006 there were .23 and .26 vacant jobs per unemployed in Storstroem and Southern Jutland, respectively, a difference of 14 percent. However, the tightness was still low in both counties and we would not expect the difference in the labor market tightness to solely explain any potential

\footnotetext{
${ }^{5}$ The largest cities by 2006 in Storstroem and Southern Jutland were Næstved (41,158 residents) and Sønderborg (27,391 residents) ranked 15th and 23rd in Denmark, respectively, in terms of residents.
} 
TABLE 2: LABOR MARKET SUMMARY.

\begin{tabular}{|c|c|c|c|c|c|c|c|c|c|}
\hline \multirow[b]{2}{*}{ County } & \multicolumn{3}{|c|}{$\begin{array}{l}\text { Avg. \# of } \\
\text { vacancies }\end{array}$} & \multicolumn{3}{|c|}{$\begin{array}{c}\text { Avg. \# of } \\
\text { unemployed }\end{array}$} & \multicolumn{3}{|c|}{$\begin{array}{c}\text { Labor market } \\
\text { tightness }\end{array}$} \\
\hline & 2006 & 2007 & 2008 & 2006 & 2007 & 2008 & 2006 & 2007 & 2008 \\
\hline Storstroem & 1,394 & 1,356 & 1,195 & 6,208 & 4,306 & 3,107 & .23 & .32 & .39 \\
\hline Southern Jutland & 1,458 & 1,361 & 1,339 & 5,680 & 3,748 & 2,352 & .26 & .36 & .57 \\
\hline
\end{tabular}

Notes: Labor market tightness calculated as the average number of vacancies divided by the average number of unemployed. The number of vacant jobs is collected by the National Labor Market Board by gathering information from the local job centers. The number of unemployed is calculated using the DREAM data supplied by the National Labor Market Board.

differences between short term treatment effects in Storstroem versus Southern Jutland. In the long term, however, there is a stronger difference in the labor market tightness between the two counties with .39 vacant jobs per unemployed worker in Storstroem and .57 vacant jobs per unemployed worker in Southern Jutland (a difference of 47 percent). In other words, there is, ceteris paribus, easier access to vacant jobs in Southern Jutland than in Storstroem county in 2008. Given these market tightnesses, we would generally expect workers in Southern Jutland to have better outside options than workers in Storstroem, and so we would expect more positive results in Southern Jutland than in Storstroem.

\subsection{The Trial Setting}

The RCT consisted of an intensification of the 2005 ALMP system. In contrast to the non-treated, treated individuals were exposed to: (i) a two-week Job Search Assistance (JSA) program, (ii) frequent meetings with a case worker, and (iii) earlier entry into labor market training. The RCT setting was constructed by randomly assigning a fraction of newly unemployed (UI benefit eligible) individuals to a treatment group by day of birth. If born between the 1st and the 15th of any given month, he was assigned to the treatment group.

There was no publicly announced description of the RCT before it was implemented. The participants in the control group were not told they were put into a control group of an $\mathrm{RCT}$ and individuals in the treatment group were notified by letter that they participated in a pilot study a week and a half after registering as unemployed and thus entering the trial.

This particular RCT constitutes a good background for the analysis in this paper as the random assignment eliminates selection into treatment groups and thus delivers identification of treatment impacts on earnings directly. Other studies have already shown QB to have positive (negative) short term effects for men (women) in terms of the exit rate out of unemployment and to lower the probability of re-entering unemployment for men 


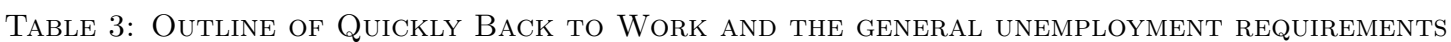

\begin{tabular}{lll}
\hline $\begin{array}{l}\text { Week of unem- } \\
\text { ployment }\end{array}$ & Treated & Non-treated \\
\hline $1-4$ & Basic registration meeting with case worker & Basic registration meeting with case worker \\
$5-8$ & Two-week JSA programme & Idle \\
$9-15$ & Frequent meetings with case worker & One meeting with case worker \\
$16-17$ & Idle & Idle \\
$18-30$ & Training program & One meeting with case worker \\
$31-39$ & Post-treatment & One meeting with case worker \\
40 & Transferred to normal scheme & Idle \\
$41-52$ & One meeting with case worker & One meeting with case worker \\
$52-208$ & Meetings with case worker every 13 weeks & Meetings with case worker every 13 weeks \\
& and labor market training every 26 weeks & and labor market training every 26 weeks \\
\hline
\end{tabular}

(see Graversen and van Ours (2008a,b), Blasco and Rosholm (2011), Vikström, Rosholm, and Svarer (2013)). However, there is no study investigating both short and long term impacts of the early effort on earnings. Even though we now know that QB had positive effects on the exit rate from unemployment for men in the short term, which would lead us to suspect positive effects on earnings as well, it is no guarantee that such effects are prolonged to the medium and long term. Card et al. $(2010,2015)$ e.g. find that studies of labor market policies with zero or negative short term effects can have positive long term effects. We thus follow up and describe effects of QB not only in the short term, but also in the medium and long term.

A fundamental feature of $\mathrm{QB}$ was that it consisted of sequential treatments causing it intractable to identify whether e.g. it was the meetings with a case worker having an impact or it simply was that the JSA program had a delayed effect. However, we argue, analyzing whether early interventions have long term labor market outcome effects provides important knowledge and insight into the full impacts of ALMP schemes. Given the structure regarding timing of treatments, we would expect the first treatment - the two-week JSA program - to comprise most of any potential impacts.

Although QB was conducted at the same time in Storstroem and Southern Jutland, there was not perfect alignment between them as they differed in two aspects. (1) The meeting frequency differed between the two counties such that in Storstroem county the treatment participants were to meet with a case worker once every week between week 9 and 15 while treated individuals from Southern Jutland should meet with their case worker once every other week. (2) Southern Jutland primarily made use of private providers to carry out the frequent meetings while Storstroem conducted the meetings in-house. These differences between the counties de-facto means that QB was not one but two RCTs, and the analysis in this paper is thus carried out for each of the counties separately. 
Despite the intended meeting intensity, the actual intensity was somewhat less, but still higher in Storstroem than in Southern Jutland. Rosholm (2008) shows that the weekly meeting intensity was .3 to .4 for treated and .1 for non-treated during week 9 to 15 of the unemployment spell in Storstroem and .3 (.1) for treated (non-treated) in Southern Jutland.

The RCT exploited in this paper has previously been used to analyze unemployment exit- and reentry-rates. Graversen and van Ours (2008a,b) find that treated individuals experienced shorter unemployment durations. They use a mixed proportional hazard model and find a 30\% higher exit rate to employment for treated participants compared to non-treated. Rosholm (2008) finds a similar estimate on the exit rate out of unemployment, but also shows that when controlling for time-varying indicators of treatment, all positive effects vanish and some even become negative, the so-called lock-in effect. He finds that the estimated risks of meetings and being activated drive the difference in the job finding rates between treated and non-treated individuals. Vikström et al. (2013) use non-parametric bounds on the estimates, developed by Vikström, Ridder, and Weidner (2015), to separate the sub-treatment effects on the exit rate out of unemployment. They find that job search assistance, frequent meetings and labor market training threats have positive impacts on the exit rate. Gautier, Muller, van der Klaauw, Rosholm, and Svarer (2012) examine the outcomes for non-treated unemployed workers and compare these with unemployed workers in different counties of Denmark, unaffected by the RCT, to measure general equilibrium effects on job finding rates. They find evidence of negative spillovers from treatment. Specifically, they find that estimating effects of treatment without accounting for externalities will result in an upward biased estimate. Finally, Blasco and Rosholm (2011) analyze long term effects on post-unemployment employment stability in terms of duration on self-support after leaving the unemployment pool. They find that treatment increases the post-unemployment self-support duration by ten percent for men while treated women show no post-unemployment stability effects. Decomposing the effect, they show that 20-25 percent is due to lagged duration dependence in the sense that treated find jobs faster, and short lagged unemployment duration leads to longer employment duration. 


\begin{tabular}{lcccccc}
\hline & \multicolumn{2}{c}{ Deleted } & \multicolumn{3}{c}{ Sample } \\
\cline { 2 - 2 } \cline { 5 - 6 } & Treated & Non-treated & & Treated & Non-treated & Individuals \\
\hline Individuals entering unemployment & & & & 2,542 & 2,638 & 5,180 \\
Miss-placement in treated/non-treated groups & $12(.5 \%)$ & $15(.6 \%)$ & & 2,530 & 2,623 & 5,153 \\
Work sharing arrangements or bad weather & $20(.8 \%)$ & $23(.9 \%)$ & & 2,510 & 2,600 & 5,110 \\
Moved abroad or died & $22(.9 \%)$ & $24(.9 \%)$ & & 2,488 & 2,576 & 5,064 \\
\hline
\end{tabular}

\subsection{THE DATA}

We use administrative data covering all individuals who entered unemployment in Southern Jutland and Storstroem between November 2005 and February 2006. Our data include: (i) Information of participation in the randomized controlled trial QB inclusive of time of entry into and exit out of unemployment down to a weekly level. (ii) Employment information covering earnings down to a quarterly level. (iii) socio-economic information including educational attainment, previous labor market experience, occupation, age, and marriage. These are recorded at a yearly level.

Table 4 outlines how we have trimmed the data. The sample consists of all newly unemployed workers in the two counties, i.e. all individuals who became unemployed during the trial window of November 2005 to February 2006 - and - at the time of registering as unemployed were entitled to the maximum period of UI benefits - four years. In total 5,180 individuals registered as newly unemployed during the trial window, split into 2,542 assigned to treatment and 2,638 to be controls. Of these, 12 treated and 15 non-treated appears to have been placed in the wrong group conditional on their day of birth and are thus deleted from the sample. 43 persons are listed as unemployed as a result of special work sharing arrangements or have been sent home due to bad weather conditions for a temporary period of time. These conditions entitle them to UI benefits, but do not count as regular unemployment in the trial sense. They are thus also deleted. Finally, we record that 22 treated and 24 non-treated either moves abroad or dies within our time period and are removed from the sample. We are thus left with a sample of 5,064 individuals of which $49.13 \%$ are placed in the treatment group after trimming the data compared to $49.07 \%$ before.

Table 5 shows key summary statistics on the sample divided into gender and counties. The sample primarily consists of workers with lower secondary or vocational educational degrees, on average they are in their late thirties and have accumulated on average 9-13 years of employment experience. The differences regarding age experience, and educational 
TABle 5: Descriptive SUmMary OVER Key EXPLAining VARIABles

\begin{tabular}{|c|c|c|c|c|c|c|c|c|c|c|c|c|}
\hline & \multicolumn{6}{|c|}{ Men } & \multicolumn{6}{|c|}{ Women } \\
\hline & \multicolumn{3}{|c|}{ Southern Jutland } & \multicolumn{3}{|c|}{ Storstroem } & \multicolumn{3}{|c|}{ Southern Jutland } & \multicolumn{3}{|c|}{ Storstroem } \\
\hline & Non-tr. & Tr. & p-val. & Non-tr. & Tr. & p-val. & Non-tr. & Tr. & p-val. & Non-tr. & Tr. & p-val. \\
\hline Individuals & 689 & 665 & & 816 & 795 & & 538 & 544 & & 533 & 484 & \\
\hline Avg. age & 39.0 & 39.7 & .280 & 41.0 & 40.9 & .866 & 39.3 & 38.4 & .203 & 39.2 & 39.6 & .572 \\
\hline Avg. experience & 12.1 & 12.4 & .401 & 13.8 & 13.7 & .604 & 10.1 & 9.2 & .027 & 10.6 & 10.5 & .798 \\
\hline Married & .40 & .44 & .137 & .43 & .41 & .418 & .54 & .56 & .511 & .51 & .54 & .340 \\
\hline Lower secondary & .38 & .38 & 1.000 & .39 & .35 & .098 & .31 & .35 & .162 & .28 & .30 & .484 \\
\hline High school & .04 & .03 & .309 & .04 & .04 & 1.000 & .07 & .06 & .511 & .08 & .08 & 1.000 \\
\hline Vocational & .49 & .50 & .713 & .51 & .52 & .688 & .45 & .41 & .184 & .44 & .45 & .750 \\
\hline Bachelor equivalent & .07 & .08 & .488 & .06 & .08 & .110 & .16 & .16 & 1.000 & .17 & .15 & .389 \\
\hline Master or above & .01 & .01 & 1.000 & .01 & .02 & .059 & .01 & .02 & .191 & .03 & .02 & .320 \\
\hline \# of qtr's employed & 3.63 & 3.70 & .171 & 3.69 & 3.71 & .625 & 3.44 & 3.46 & .784 & 3.50 & 3.43 & .333 \\
\hline Avg. qtr. earnings & 65,902 & 64,957 & .515 & 69,328 & 67,727 & .234 & 52,361 & 51,242 & .459 & 53,849 & 54,419 & .708 \\
\hline
\end{tabular}

Notes: Non-tr.: Non-treated individuals. Tr.: Treated individuals. p-val.: p-value from test for difference in means. Lower secondary education are workers who have either not started or finished high school, bachelor equivalent corresponds to some college and master or above to college level. \# of quarters employed and average quarterly earnings are measured over the last four quarters before entering the unemployment spell that triggered participation in the trial.

Figure 1: QuANTILE DiffERENCES BETWEen TREATED AND NON-TREATED AVERAGE QUARTERLY EARNINGS, ONE TO FOUR QUARTERS BEFORE ENTERING UNEMPLOYMENT

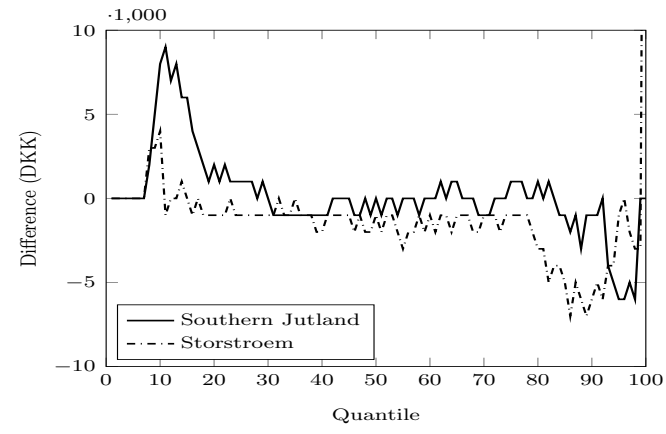

(a) Men

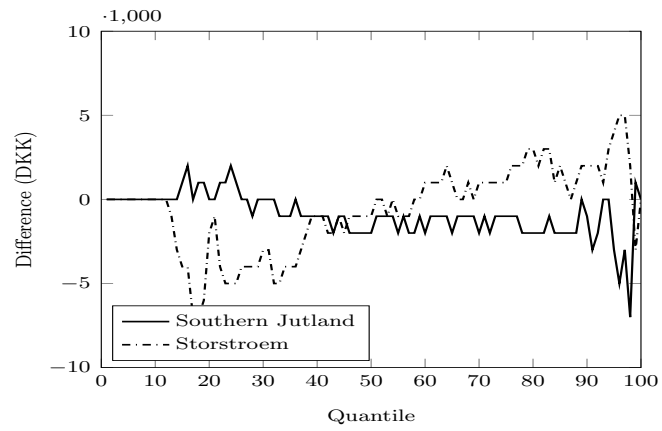

(b) Women

attainment are statistically insignificant on a five percent level for all categories. However, what we can also see in Table 5 is that we need to treat men and women as different samples and Southern Jutland and Storstroem as different samples. Men are relatively more experienced than women and individuals from Storstroem are more experienced than individuals in Southern Jutland at the time of entering unemployment. We also see some statistically insignificant differences in the educational levels for treated versus non-treated individuals. Finally, women entering unemployment are more likely to be married than men entering unemployment during the trial window. ${ }^{6}$

Since the outcome in this paper is earnings after participating in QB it is important to check for individual earnings before entering the trial as well. If e.g. the random assignment procedure had over-represented workers with low pre-treatment earnings to the

\footnotetext{
${ }^{6}$ Comparing these statistics with the corresponding statistics before removing observations according to Table 4 (not shown, but available upon request) reveals no significant differences. It is thus not the trimming of data that causes differences between treated and non-treated and the two counties.
} 
control group and we did not include this into our identification strategy, then we would end up overestimating effects of treatment. Therefore, Table 5 also shows average number of quarters employed and average quarterly earnings during the last four quarters before entering unemployment. Men, regardless of treated/non-treated on average earned 65,000 69,000 DKK per quarter while women on average earned 51,000 - 54,000 DKK per quarter - corresponding roughly to full time earnings for an unskilled worker. ${ }^{7}$ The numbers reveal no statistically significant differences between treated and non-treated before the trial. However, although there are no average differences, there might be distributional differences. To check for distributional differences, Figure 1 shows the average quarterly earnings by quantiles for men and women in Southern Jutland and Storstroem. Around ten percent have no earnings in the last four quarters before entering the trial. It was a requirement for entering the trial that the individual worker was entitled to a full period of UI benefits. This does not necessarily mean that he or she should be working full time up until entering unemployment, though, as e.g. students who are members of a UI fund were also eligible. Figure 1 shows that there are indeed distributional differences within gender and county across treatment/non-treatment status. Low quantiles for men relate to higher earnings among treated than non-treated while the opposite is the case for high quantiles. Also women in Storstroem reveal differences, only here in the opposite direction. To make sure that these (on average insignificant) differences does not drive the results, we weight our estimates with inverse propensity scores.

Besides controlling for earnings prior to entering the unemployment spell that triggered participation in $\mathrm{QB}$, we also include hours worked and various socio-economic information, including dummies for marriage, occupational position during 2004 and educational degree, age, age squared, experience and experience squared when entering unemployment into the conditioning set. After estimating the propensity score for each individual we calculate an individual weight to be used in the final analysis as the inverse propensity score.

\section{Ex Ante Expectations}

When advancing an ALMP system we would expect effects to appear in two ways: (i) The extra effort taken towards an unemployed worker should help build/rebuild skills and abilities needed to find and master a job. I.e. the effects follow from building upon human

\footnotetext{
${ }^{7}$ In 20061 US dollar were around 5.7 Danish kroner.
} 
capital or by the removal of labor market frictions. (ii) Leisure time while unemployed is being taxed away, promoting the unemployed's search effort. Below, we go through how we ex ante would expect effects of the RCT to come about if it were (i) or (ii) that were dominating.

\subsection{Human Capital and the Removal of Labor Market Frictions}

According to theory, building upon human capital and removing labor market frictions, should actively help the unemployed worker towards better worker-firm matches. It might take some time, though, to acquire skills which may prolong unemployment and hence lower short term earnings. On the other hand, when a job is found, it is likely to have a prolonging effect on employment duration. We thus expect a positive impact on earnings in the medium to long term. Regarding effect expectation on the updated skill side, we need to go into the treatment structure. In the labor market context of 2005 and 2006, workers entering unemployment should participate in a short basic registration meeting and four meetings with a case worker during the first 30 weeks of unemployment.

QB consisted of three treatments, which all might build upon human capital/remove frictions, which otherwise induce difficulties to find matches between unemployed workers and vacant positions. If the unemployed worker e.g. train to perform better at interviews or to target vacancies, he can increase the probability of receiving an acceptable job

offer. Job search assistance programs can thus assist the unemployed worker to find job offers matching his personal specifications, and enhance the probability of him leaving unemployment for employment. An early JSA program is therefore expected to lower the unemployment to employment duration, which increases the number of hours worked and thus earnings. Equally important, ceteris paribus, an early JSA program should aid the worker to find a good worker-firm match and the JSA effect is expected to be mainly positive on earnings. However, moving any labor market program to the early stages of an unemployment spell risks that unemployed workers close to the labor market, who themselves would easily find new employment, end up spending more time unemployed than otherwise. In this way, the JSA program might prolong unemployment, and thus lower short term earnings. Even if the JSA program prolongs unemployment, however, we would expect the worker to be better at matching with firms so we should see positive medium to long term effects. 
When meeting with a case worker the unemployed worker has the possibility of discussing several issues. He can be updated with the current status of the local labor market, he can be advised as to other industries in need of labor, possibilities of updating human capital etc. A frequent meeting structure can therefore lead the unemployed in the direction of new job prospects, which might lower short term earnings but act as a stepping stone towards better earnings in the future. The frequent meetings can also be perceived as such a burden to the unemployed worker that he chooses to opt into any job, which might be a lower paying job than without the meetings. Such a path could be long lasting turning into negative short and long term earnings effects. Dolton and O'Neill (1996) examine the controlled experiment Restart conducted in the UK in 1989, in which workers who had been unemployed for six months were randomly selected to either participate in interviews with a PES office or not. They show that participating in interviews reduced overall unemployment duration. They also showed a strong threat effect of the meetings as well as improved chances for exiting from unemployment to employment. We would mainly expect zero or negative short term but ambiguous long term earnings effects.

Lastly, The early entry into labor market training has the possibility of affecting earnings in diverse respects. First, if an unemployed worker during the training scheme is building on his human capital in a manner of direct usage for a specific industry he might end up finding a job with positive short and long term earnings effects. If he has to change industry, the short term effects might be negative but acting as a stepping stone towards positive long term earnings effects. On the other hand, training can be such that it contributes with no usable human capital and at best does not affect earnings in either the short or the long term. Lastly, the training schemes might be perceived so intimidating that the unemployed worker opts out to any job, which might lower his earnings in the short term and possibly also in the long term, or it could rise earnings simply because working at a lower paying job for two weeks longer than a higher paying job might compensate when measuring total earnings.

As section 2 shows, the RCT setting was a mixture of intensifications of the labor market program in three dimensions; a two-week JSA program early in the unemployment spell, frequent meetings with a case worker, and earlier entry into a training scheme. The three treatments cannot be separated and if e.g. one treatment has positive effects but another has negative, then the estimated outcome will be a composition effect, and which 
dominates will be an empirical question. We do know, however, the rough timing of the treatments and the sequence of the treatments were such that first came the twoweek JSA program, then frequent meetings with a case worker and lastly a labor market training program. I.e., since no worker would enter a treatment unless he/she remained unemployed until the start of the treatment, we know that more workers experienced the JSA program than the frequent meetings and again than entering labor market training. We would thus ex ante place more emphasis on the possible effects of the JSA program than on the meetings and lastly on the labor market training.

Although the setup of the programs were not dependent on the earnings of the unemployed workers prior to entering unemployment, it is likely that early intervention has heterogeneous effects across the earnings distribution. If the level of prior earnings is a signal of worker skills, then a worker in the top half of the earnings distribution is more likely to be able to find a new job him self without accumulating more human capital than a worker in the bottom half. On the other side, workers in the top half of the earnings distribution might also be those most prone to take in learning from labor market programs and to capitalize on the removal of labor market frictions, why it is not unlikely that this dimension would benefit high earners the most.

\subsection{TAXing Leisure Time}

While building upon human capital and removing labor market frictions lead to better worker-firm matches, taxing leisure time is more likely to be working as an incentive to shorten unemployment. This might have positive effects on short term earnings, but zero or negative effect on the worker-firm match and thus a short term effect on earnings should vanish in the medium to long term. These stylized effects might also depend on the unemployed workers' position in the earnings distribution, as UI benefits are dependent on former earnings. In the Danish UI system, as a basis, an unemployed worker is entitled to 90 percent of his former earnings (net of a gross tax of $8 \%$ ) up to a maximum threshold of $B{ }^{8}$ If 90 percent of his earnings before registering as unemployed is below 82 percent of $B$, he receives $.82 B$. This means that the replacement rate is heterogeneous in former earnings, and so will utility while unemployed be. The amount of time an unemployed

\footnotetext{
${ }^{8}$ The quarterly level of $B \approx 42,000$ DKK equivalent to around 8,000 USD in 2006 corresponding to pre-unemployment quarterly earnings of at least 51,000 DKK in order to reach the maximum benefit level $(51,000(1-.08) .90 \approx 42,000)$. Consequently, quarterly earnings below $42,000 \mathrm{DKK}$ before gross tax entitled the worker to $.82 B$ since $42,000(1-.08) .90 \approx .82 B$.
} 
Figure 2: Stylized Utility OF UnEMPLOYMENT AS FUnCTION OF $.9 \times$ PRE-UNEMPLOYMENT EARNingS AND FIXED LEISURE TIME LEVELS FOR TREATED (T) AND NON-TREATED (N)

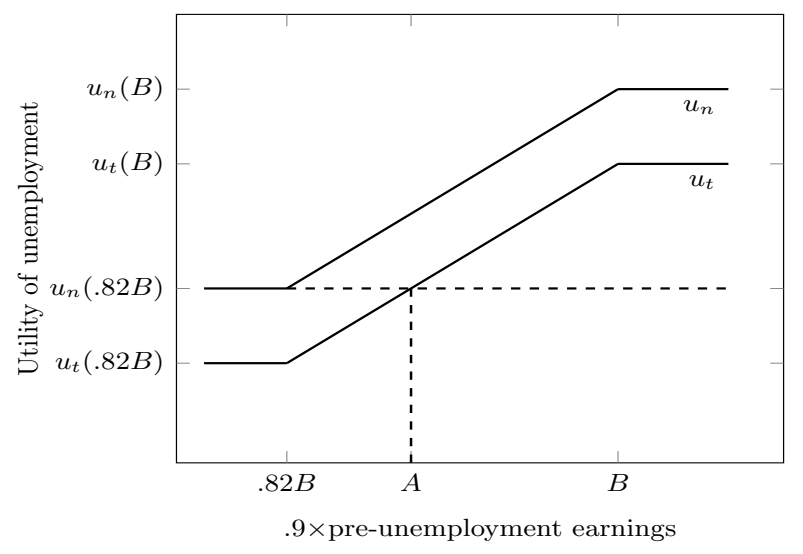

worker is required to devote to ALMP is independent on his prior earnings, so the utility of leisure time while unemployed should be constant across prior earnings. We can therefore assume utility to be a piecewise linear function of UI benefits and leisure time. Figure 2 portrays a stylized version of such utility for non-treated, $u_{n}$, and treated, $u_{t}$, over the prior earnings distribution. All workers entering unemployment and drawn into the treatment group of QB will in this stylized example thus be worse off than if he had been placed in the control group with the same UI benefit level but with more leisure time on his hands. This leaves the treated with an incentive to search harder for a new job than non-treated. Additionally, given the lower overall utility while unemployed, treated workers will consequently lower their reservation wages and accept jobs with higher utility than $u_{t}$ but lower than $u_{n}$. This path entails positive short term effects. Clearly, if the program had no other intervention but to tax away leisure time, we would not expect the treated worker to perform better in terms of worker-firm matches than non-treated in the medium to long term, so we should see no medium to long term effects. We would therefore only expect positive short term effects on earnings as a result of taxing leisure time.

Because of the non-linear utility function it is, moreover, likely that taxing leisure time has heterogenous effects across prior earnings. Figure 2 shows that all workers put into the treatment group loose the same nominal level of utility, however in real terms, the lower the level of prior earnings, the more relative utility you loose. On top of this, even though all workers loose utility because of treatment, workers with prior earnings above point $A$ are simply being handed utility equivalent to having had lower prior earnings, but workers below point $A$ receive a lower utility than the lowest possible they could have 
expected when entering unemployment. We would therefore overall expect all workers to respond to the taxing of leisure time, but the low earners to respond the most.

To sum up on ex ante expectations, if effects of participating in a program like QB were negative to zero or slight positive in the short term and positive in the medium and long term, we would then administer them to be the result of improved worker-firm matches through the accumulation of human capital and/or removal of labor market frictions. If instead we see positive short term effects but no medium and long term effects, there is evidence suggesting that the program worked primarily through taxing the leisure time of unemployed workers leading them to search harder for a job and accept otherwise unattractable job offers. We also expect treatment to affect workers differently across the earnings distribution. Accumulation of human capital and removing labor market frictions might benefit high earners the most while taxing of leisure time should primarily affect low earners.

\section{Methodology}

In its nature, an RCT delivers causal effects of treatment directly. However, as we have seen there are statistically insignificant differences between treated and non-treated prior to entering the trial that we wish to control for in order to increase our confidence to our estimates. We do this using propensity scores. Following Bitler et al. (2006) we also allow for heterogeneous effects within the earnings distribution and estimate quarterly impacts on quantiles.

We start by estimating propensity scores using logit regressions for each individual divided into our four samples; (i) men in Southern Jutland, (ii) men in Storstroem, (iii) women in Southern Jutland, and (iv) women in Storstroem. The logit regressions deliver estimated propensities of treatment, $\hat{\rho}$, which we use to calculate weights for each individuals. I.e. for individual $i$ with treatment dummy $T_{i}$ and estimated propensity score $\hat{\rho}_{i}$, his weight $\hat{\omega}_{i}$ is calculated as

$$
\hat{\omega}_{i}=\frac{T_{i}}{\hat{\rho}_{i}}+\frac{1-T_{i}}{1-\hat{\rho}_{i}} .
$$

We then use this weight to estimate earnings distributions. As we distinguish between 
short, medium, and long term, we need to set up time horizons as well. Let short term denote one to four quarters after entering the trial, medium term denotes five to eight quarters and long term denotes nine to eleven quarters after entering the trial. Let $S$ denote the set of quarters in our time horizon, $S \in\left\{\left(q_{1}, q_{2}, q_{3}, q_{4}\right),\left(q_{5}, q_{6}, q_{7}, q_{8}\right),\left(q_{9}, q_{10}, q_{11}\right)\right\}$ while $S_{q}$ denotes the number of quarters in $S$. The distribution of earnings in each of our samples for treated and non-treated is defined as

$$
\hat{F}_{c, g, t}(y) \equiv \frac{1}{N_{c, g} S_{q}} \sum_{i=1}^{N_{c, g}} \sum_{s \in S} \hat{\omega}_{i} \mathbb{1}\left(T_{i}=t\right) \mathbb{1}\left(Y_{i, s} \leq y\right),
$$

where $c \in\{$ Southern Jutland, Storstroem $\}, g \in\{$ men, women $\}$, and $t \in\{0,1\}$ specifies the county, gender, and treatment respectively. $N_{c, g}$ measures the number of individuals in the sample and $Y_{i, s}$ is the realized earnings of individual $i$ during quarter $s$. Lastly, $\mathbb{1}$ is the indicator function. Having defined earnings distributions, we can estimate the $j$ 'th specific quantile $\left\{\hat{y}_{j, t}\right\}_{j=1}^{100}$ as

$$
\hat{y}_{j, t} \equiv \inf \left\{y: \hat{F}_{c, g, t}(y) \geq j\right\}
$$

With specified quantiles for both treated and non-treated individuals in each sample, we estimate Quantile Treatment Effects (QTE), $\hat{\Delta}_{j}$, as the difference between treated and non-treated, i.e.

$$
\hat{\Delta}_{j} \equiv \hat{y}_{j, t=1}-\hat{y}_{j, t=0}
$$

We also estimate Average Treatment Effects (ATE) as

$$
A T E \equiv \frac{1}{N_{c, g} S_{q}} \sum_{i=1}^{N_{c, g}} \sum_{s \in S} \hat{\omega}_{i} Y_{i, s}\left[\mathbb{1}\left(T_{i}=1\right)-\mathbb{1}\left(T_{i}=0\right)\right]
$$

Confidence intervals on our QTEs are estimated by a bootstrap procedure of 1,000 replications given by following a number of steps:

A) We randomly draw $N_{c, g}$ individuals with replacement from the sample $(c, g)$. With each individual we keep hold on all pre-treatment observables and information on treatment and quarterly earnings to form a bootstrap sample.

B) We estimate propensity scores for treatment and compute the connected weights for 
each observation in the bootstrap sample. Note that, if an individual is drawn into the sample $k$ times he will stay in the sample acting as $k$ individuals with the same observed variables and outcomes.

C) Given the estimated weights in the bootstrap sample, we estimate bootstrap QTEs.

After the 1,000 replications, for each quantile, we sort the estimated QTEs from lowest to highest, and denote the $95 \%$ confidence interval as the interval bounded below by the 26 th lowest value and above by the 975 th highest value. ${ }^{9}$

\section{$5 \quad$ Results}

In this section we present our findings on the average and quantile treatment effects of participating in $\mathrm{QB}$ on post-unemployment earnings.

\subsection{Average Treatment Effects}

Table 6 shows estimated average treatment effects on quarterly earnings and on the number of quarters with employment one, two, and three years after entering unemployment. A quarter with employment is defined as a quarter with positive earnings. The table shows both weighted and unweighted estimates. First, we see that weighting earnings alters the estimates only slightly while there are some differences in weighted and unweighted estimates of quarters employed. Since we see some statistical differences between weighted and unweighted estimates, we hereafter focus on weighted estimates. In the short term average treatment effects on earnings are statistically significantly positive of around 4,000 DKK for men and insignificant at the $5 \%$ level for women. It seems to be somewhat driven by treatment increasing the average number of quarters employed. Medium and long term earnings are only affected by the treatment for men in Southern Jutland, while the average impact has vanished for men in Storstroem during quarters 5 to 8 and 9 to 11 . The magnitude of treatment impacts grows from short term to medium and long term for men in Southern Jutland. This might be caused by the fact that quarters employed are increased in the short term which gives rise to an indirect effect since extra employment delivers more experience and human capital which again might increase future earnings.

\footnotetext{
${ }^{9}$ With 1,000 replications, and sorted lowest to highest, the $2.5 \%$ lowest values will be the first 25 values and the $2.5 \%$ highest values will be the last 25 values, i.e. values 976 to 1,000.
} 
The overall picture shows that workers in Southern Jutland gain more from treatment than workers in Storstroem and men gain more than women. The county difference is consistent with labor market tightnesses shown in Table 2. Besides the labor market tightness difference, Southern Jutland used private providers to carry out the meetings while Storstroem had them in-house. If the case workers hired by private providers were more specialized in holding meetings with unemployed workers than those at the PES then we would see results across counties equivalent to the ones in Table 6 . The results of positive short term effects and statistically insignificant medium and long term effects for men in Storstroem and (insignificantly) for women suggest that for these samples it is the taxing of leisure time that is the main driver of the effects. For men in Southern Jutland, the evidence goes towards human capital accumulation and/or removal of labor market frictions. The effects are also in line with the results of Graversen and van Ours (2008b), Rosholm (2008), and Blasco and Rosholm (2011) who find QB to shorten unemployment duration for men and women, and to lengthen subsequent short term employment duration for men.

\subsection{Quantile Treatment Effects}

Figure 3 shows quantile treatment effects on earnings in the short term (the first to fourth quarter after entering unemployment) estimated for men and women in Southern Jutland and Storstroem county (solid lines - left axis). Bootstrapped 95\% confidence intervals (dash-dotted lines - left axis) together with treated and non-treated earnings quantiles (dashed and dotted lines respectively - right axis) are also shown. The first quarter represents the first calendar quarter after the quarter in which the individual worker enters unemployment.

The first observation is that approximately 10 percent of men and 20 percent of women have no earnings during the first to fourth quarter, which explains the zero differences in the bottom earnings distributions. Second, examining the same trial, Graversen and van Ours (2008b) find that the exit rate to employment rose considerably during the first eight to twelve weeks after entering unemployment for the treated, and especially so for men. I.e. we should expect treatment to have positive effects on earnings in the low end of the distribution, as this means more treated than non-treated spend time employed and will thus be able to extract earnings. This is exactly the pattern that 
TAble 6: Average treatment efFects on QUARTERly EARnings (DKK) AND EMPloyment (QUARTERS WITH POSITIVE EARNINGS)

\begin{tabular}{|c|c|c|c|c|c|c|c|c|}
\hline \multirow[b]{3}{*}{ Men } & \multicolumn{4}{|c|}{ Avg. quarterly earnings } & \multicolumn{4}{|c|}{ \# of quarters employed } \\
\hline & \multicolumn{2}{|c|}{ Unweighted } & \multicolumn{2}{|c|}{ Weighted } & \multicolumn{2}{|c|}{ Unweighted } & \multicolumn{2}{|c|}{ Weighted } \\
\hline & Non-tr. & ATE & Non-tr. & ATE & Non-tr. & ATE & Non-tr. & ATE \\
\hline \multicolumn{9}{|l|}{ Southern Jutland } \\
\hline 1st -4 th quarter & 51,011 & $\begin{array}{c}4,201^{* * *} \\
(1,456)\end{array}$ & 51,001 & $\begin{array}{c}4,298^{* * *} \\
(1,391)\end{array}$ & 3.41 & $\begin{array}{c}.159^{* * *} \\
(.058)\end{array}$ & 3.43 & $\begin{array}{l}.132^{* *} \\
(.063)\end{array}$ \\
\hline 5 th -8 th quarter & 58,264 & $\begin{array}{c}3,939 * * \\
(1,643)\end{array}$ & 58,348 & $\begin{array}{c}3,950^{* *} \\
(1,633)\end{array}$ & 3.43 & $\begin{array}{c}.187^{* * * *} \\
(.060)\end{array}$ & 3.45 & $\begin{array}{l}.157^{* *} \\
(.065)\end{array}$ \\
\hline 9 th -11 th quarter & 56,604 & $\begin{array}{c}4,895^{* * *} * \\
(1,789)\end{array}$ & 56,832 & $\begin{array}{c}4,885^{* * *} * \\
(1,729)\end{array}$ & 2.52 & $\begin{array}{l}.099^{*} \\
(.053)\end{array}$ & 2.54 & $\begin{array}{l}.072 \\
(.057)\end{array}$ \\
\hline \multicolumn{9}{|l|}{ Storstroem } \\
\hline 1st -4 th quarter & 53,014 & $\begin{array}{c}3,845^{* * *} \\
(1,417)\end{array}$ & 52,730 & $\begin{array}{c}4,243^{* * *} \\
(1,297)\end{array}$ & 3.41 & $\begin{array}{c}.161^{* * *} \\
(.053)\end{array}$ & 3.42 & $\begin{array}{c}.145^{* * *} \\
(.054)\end{array}$ \\
\hline 5 th -8 th quarter & 58,719 & $\begin{array}{c}2,594 \\
(1,670)\end{array}$ & 58,507 & $\begin{array}{l}2,783^{*} \\
(1,524)\end{array}$ & 3.34 & $\begin{array}{l}.100 \\
(.062)\end{array}$ & 3.34 & $\begin{array}{l}.081 \\
(.062)\end{array}$ \\
\hline \multirow[t]{3}{*}{ 9th - 11th quarter } & 57,211 & $\begin{array}{c}1,471 \\
(1,793) \\
\end{array}$ & 56,989 & $\begin{array}{c}1,601 \\
(1,692) \\
\end{array}$ & 2.44 & $\begin{array}{l}.038 \\
(.056) \\
\end{array}$ & 2.44 & $\begin{array}{c}.034 \\
(.057) \\
\end{array}$ \\
\hline & \multicolumn{4}{|c|}{ Avg. quarterly earnings } & \multicolumn{4}{|c|}{ \# of quarters employed } \\
\hline & Unv & ghted & $\overline{\mathrm{We}}$ & hted & $\overline{\mathrm{Unw}}$ & ghted & Wei & ited \\
\hline \multicolumn{9}{|l|}{ Women } \\
\hline \multicolumn{9}{|l|}{ Southern Jutland } \\
\hline 1st - 4th quarter & 37,081 & $\begin{array}{c}1,651 \\
(1,411)\end{array}$ & 37,071 & $\begin{array}{c}1,970 \\
(1,389)\end{array}$ & 3.13 & $\begin{array}{l}.184^{* *} \\
(.080)\end{array}$ & 3.14 & $\begin{array}{l}.172^{* *} \\
(.084)\end{array}$ \\
\hline 5 th -8 th quarter & 45,940 & $\begin{array}{c}-2,370 \\
(1,594)\end{array}$ & 45,910 & $\begin{array}{l}-2,211 \\
(1,569)\end{array}$ & 3.32 & $\begin{array}{l}-.018 \\
(.084)\end{array}$ & 3.34 & $\begin{array}{l}-.051 \\
(.084)\end{array}$ \\
\hline 9 th -11 th quarter & 47,012 & $\begin{array}{l}-1,457 \\
(1,725)\end{array}$ & 46,745 & $\begin{array}{l}-1,134 \\
(1,629)\end{array}$ & 2.46 & $\begin{array}{l}-.044 \\
(.066)\end{array}$ & 2.46 & $\begin{array}{l}-.058 \\
(.064)\end{array}$ \\
\hline \multicolumn{9}{|l|}{ Storstroem } \\
\hline 1st - 4th quarter & 38,050 & $\begin{array}{c}790 \\
(1,465)\end{array}$ & 37,714 & $\begin{array}{c}1,045 \\
(1,443)\end{array}$ & 3.19 & $\begin{array}{l}.096 \\
(.081)\end{array}$ & 3.18 & $\begin{array}{l}.111 \\
(.087)\end{array}$ \\
\hline 5 th -8 th quarter & 44,518 & $\begin{array}{l}-1,118 \\
(1,752)\end{array}$ & 44,155 & $\begin{array}{c}-821 \\
(1,877)\end{array}$ & 3.26 & $\begin{array}{l}-.098 \\
(.089)\end{array}$ & 3.26 & $\begin{array}{l}-.104 \\
(.192)\end{array}$ \\
\hline 9 th - 11th quarter & 45,949 & $\begin{array}{c}-988 \\
(1,898)\end{array}$ & 45,903 & $\begin{array}{c}-811 \\
(4,393)\end{array}$ & 2.41 & $\begin{array}{l}-.050 \\
(.075)\end{array}$ & 2.42 & $\begin{array}{l}-.056 \\
(.193)\end{array}$ \\
\hline
\end{tabular}

Notes: ${ }^{* *},{ }^{* *}$, and ${ }^{*}$ indicates statistical significance at a $1 \%, 5 \%$, and $10 \%$ level respectively. Non-tr.: Average quarterly earnings and average number of quarters employed for non-treated individuals. ATE: Average treatment effects. Bootstrapped standard errors are shown in braces.

we find. All samples reveal both positive impacts for all quantiles and much clearer impacts in the lower quantiles. Both of these observations also concur with effects of taxing leisure time. As Graversen and van Ours find, we also find that in the short term women respond less than men towards the treatments. On the other hand, men show statistically significant short term impacts on earnings from early interventions for all quantiles below the 60th. Comparison of the quantile estimation with the average estimated impact reveals that for men in Southern Jutland the clear positive effect among quantiles 10 to 40 is underestimated by the ATE while quantiles 1 to 10 is overestimated, as none of these actually find employment during the first to fourth quarter after entering unemployment.

Graversen and van Ours (2008b) show that less than 15 percent were still unemployed 43 weeks after entering unemployment. So since most workers found employment within a year, then most treatment impacts - besides potentially an indirect experience effect found in the short term will have vanished when moving to the medium and long term, if 
Figure 3: Quantile Treatment Effects (QTE) on 1St to 4th Quarter earnings

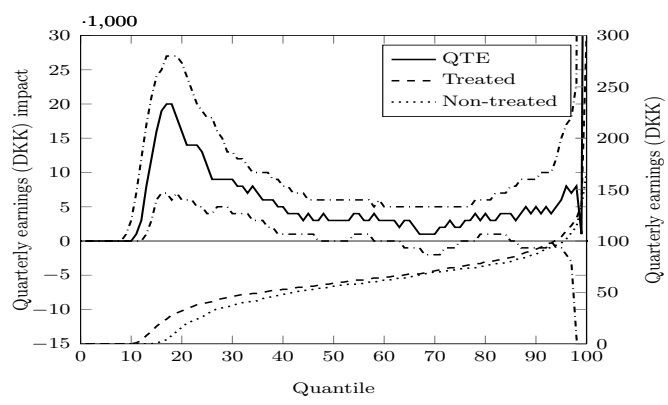

(a) Southern Jutland, men

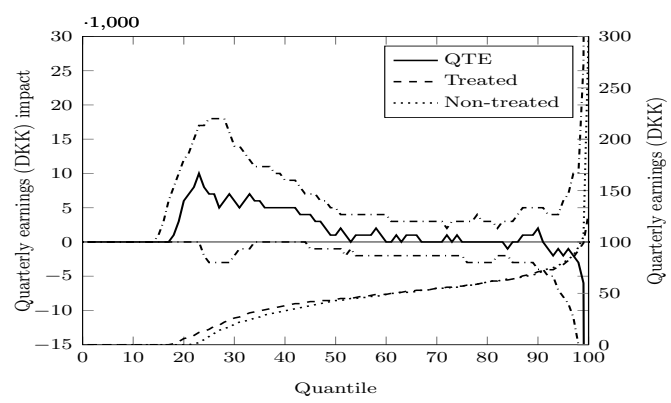

(c) Southern Jutland, women

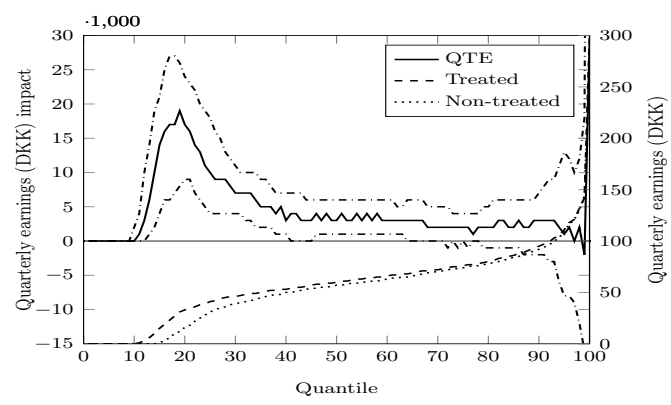

(b) Storstroem, men

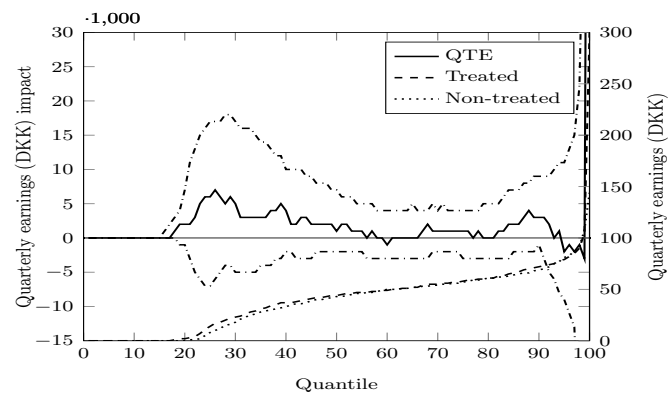

(d) Storstroem, women

Notes: Quantile Treatment Effects (QTE) are depicted on the left axis while treated and non-treated earnings refer to the right axis; dotted lines indicate $95 \%$ confidence intervals.

QB treatment had no other effect than on the exit rate to employment. Figure 4 and 5 show that this pattern indeed seems to be the case, besides for men in Southern Jutland. Men in Southern Jutland have the same pattern in the medium and long term as in the short term, indicating that the early intervention not only affected the short term exit rate to employment, but also increased the employment participation, and thus earnings five to eight quarters after entering unemployment. On the other hand, women in Southern Jutland reveal an insignificant negative impact that is relatively constant over quantiles in the medium term. In Storstroem county, men's earnings are still affected positively in the medium term, however insignificantly, while women have close to zero impacts from the early intervention in the medium and long term.

Comparing with the presented results with labor market frictions presented in Table 2 and unemployment rates in Table 1 indicate two reflections of the effects from the RCT: (i) Mens' earnings were overall more affected by treatment than womens'. This is consistent with a higher unemployment rate among women than men in both counties during the post-treatment period. (ii) In Southern Jutland, the county with lesser unemployed per vacancy during the analysis period, we saw that mens' earnings were subject to a permanent effect compared to the temporary effect for men in Storstroem. 
Figure 4: Quantile Treatment Effects (QTE) On 5Th to 8Th Quarter earnings

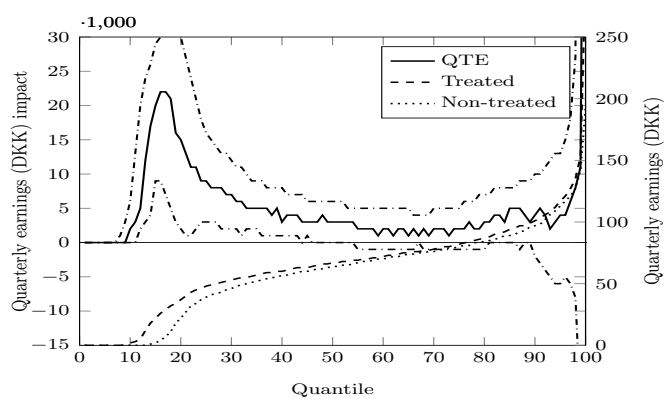

(a) Southern Jutland, men

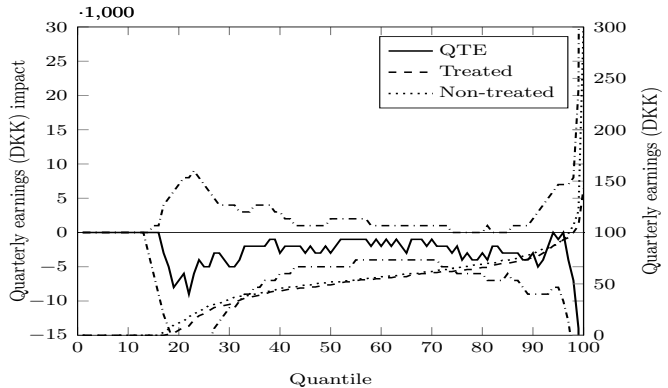

(c) Southern Jutland, women

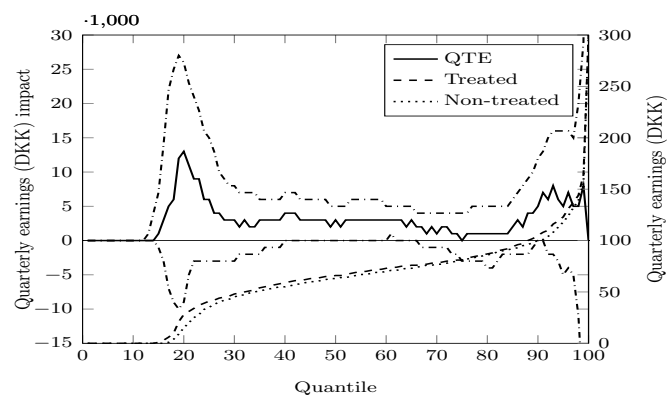

(b) Storstroem, men

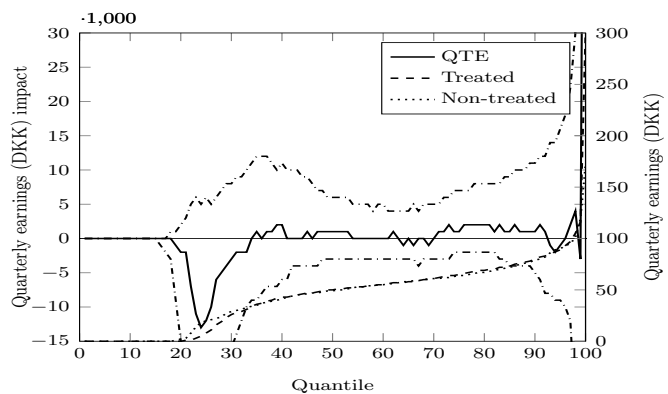

(d) Storstroem, women

Notes: Quantile Treatment Effects (QTE) are depicted on the left axis while treated and non-treated earnings refer to the right axis; dotted lines indicate $95 \%$ confidence intervals.

Figure 5: Quantile Treatment Effects (QTE) on 9Th to 11th Quarter earnings

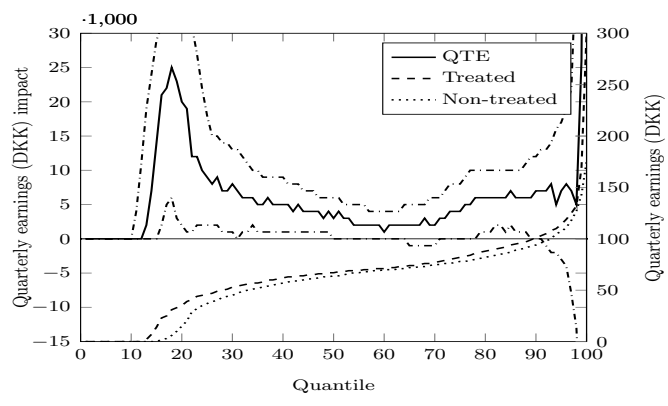

(a) Southern Jutland, men

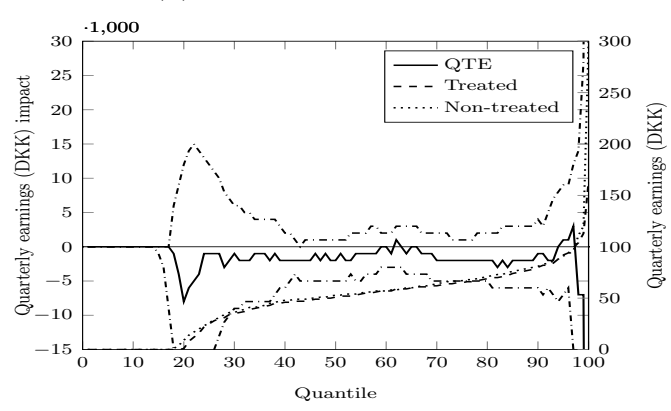

(c) Southern Jutland, women

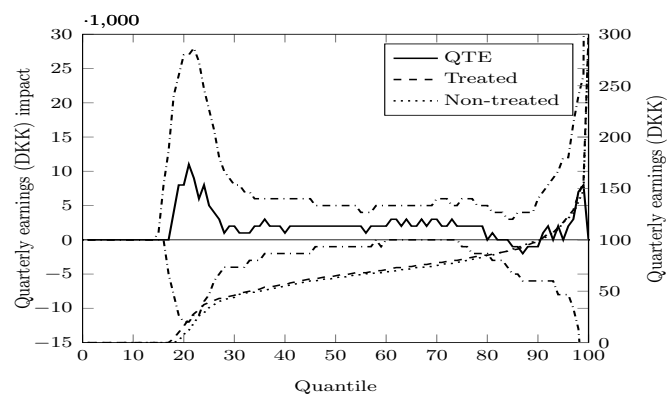

(b) Storstroem, men

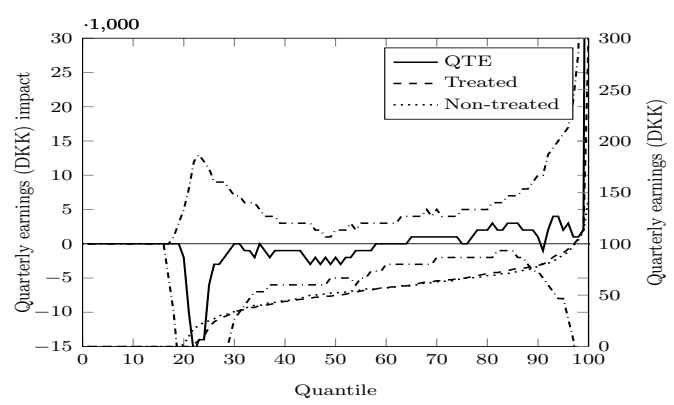

(d) Storstroem, women

Notes: Quantile Treatment Effects (QTE) are depicted on the left axis while treated and non-treated earnings are picked on the right axis; dotted lines indicate $95 \%$ confidence intervals. 
Since we find positive effects in the short term for all samples, and only medium and long term impacts in one sample, it suggests that the taxing of leisure time aspect is the dominating factor in treating with an early intervention. Had human capital or job search capabilities been improved as a result of the interventions in $\mathrm{QB}$, we would have seen substantively significant impacts of earnings not only in the short term but also in the medium and long term. We only observe such a pattern for men in Southern Jutland. However, to conclude evidence for the taxing of leisure time theory from figure 3 to 5 implies assuming that QB was rank preserving in the earnings distribution, i.e. that $\mathrm{QB}$ had impacts on earnings but no impact on where in the relative distribution an individual lies pre- and post-unemployment. Optimally, we could test this assumption by non-parametrically estimating QTE's for each pre-unemployment earnings quantile. Such a method unfortunately requires many observations in general and with samples of approximately 500 treated and 500 non-treated leaving only five individuals within each percentile it does not deliver enough power for such an estimation. Instead we estimate QTEs for three subsamples: (a) individuals with earnings less than 42,000 DKK during the last quarter before entering unemployment (Low earners), (b) individuals with earnings between 42,000 and 51,000 DKK during the last quarter before entering unemployment (medium earners), and (c) individuals with earnings higher than 51,000 DKK during the last quarter before entering unemployment (high earners). ${ }^{10}$

Table 7 shows ATE estimates on unweighted earnings for each sample in the short term. Two important questions can be answered from Table 7: (a) Is an assumption of rank preservation justified? And (b) are there evidence supporting the taxing of leisure time or the human capital dimension? Regarding (a), rank preservation would be justified if we find that low, medium, and high pre-unemployment earners on average were also low, medium, and high post-unemployment earners, respectively. Given the discussion in section 3 then, regarding question (b), if it is the taxing of leisure time aspect that is dominating, we would expect that most effects of treatment occur among low preunemployment earners. On the other hand, if treatment effects mainly come out among high pre-unemployment earners, then there is evidence towards removal of labor market frictions for those most likely to be prepared to take up a job without further training.

\footnotetext{
${ }^{10} 42,000$ DKK is chosen because it is the upper thresholds needed to receive the lowest level of benefits. Likewise, 51,000 DKK is chosen because it is the lower threshold for receiving the highest benefit level. The point $A$ from Figure 2 should thus be found within the medium earners.
} 
TABle 7: Short term AVERAGE TREATMENT EFFECTS DIVIDED INTO PRE-UNEMPLOYMENT EARNINGS GROUPS

\begin{tabular}{|c|c|c|c|c|c|c|}
\hline \multirow[b]{2}{*}{ Pre-unemployment earnings } & \multicolumn{3}{|c|}{ Men } & \multicolumn{3}{|c|}{ Women } \\
\hline & Non-treated & ATE & $\mathrm{p}$-value & Non-treated & ATE & p-value \\
\hline \multicolumn{7}{|l|}{ Southern Jutland } \\
\hline Low earners & 41,140 & $\begin{array}{c}1,017 \\
(3,252)\end{array}$ & .755 & 31,004 & $\begin{array}{c}4,747 \\
(2,004)\end{array}$ & .018 \\
\hline Medium earners & 44,522 & $\begin{array}{c}4,160 \\
(4,309)\end{array}$ & .336 & 37,754 & $\begin{array}{c}723 \\
(3,053)\end{array}$ & .813 \\
\hline High earners & 54,676 & $\begin{array}{c}5,923 \\
(1,717)\end{array}$ & .001 & 42,698 & $\begin{array}{c}-908 \\
(2,248)\end{array}$ & .687 \\
\hline \multicolumn{7}{|l|}{ Storstroem } \\
\hline Low earners & 36,566 & $\begin{array}{c}7,984 \\
(3,089)\end{array}$ & .010 & 30,606 & $\begin{array}{c}1,673 \\
(2,357)\end{array}$ & 478 \\
\hline Medium earners & 45,805 & $\begin{array}{c}3,864 \\
(3,296)\end{array}$ & .243 & 38,943 & $\begin{array}{c}-1,569 \\
(3,396)\end{array}$ & .645 \\
\hline High earners & 57,891 & $\begin{array}{c}3,007 \\
(1,696)\end{array}$ & .076 & 43,015 & $\begin{array}{c}1,310 \\
(2,096)\end{array}$ & .532 \\
\hline
\end{tabular}

errors are shown in braces and p-value indicates the statistical test for ATE different from zero.

Although most ATEs in Table 7 are insignificant, the overall picture does seem to point towards supporting rank preservation as a common feature across samples, as we see higher average post-unemployment earnings for medium earners than low earners and for high earners than for medium earners. Regarding evidence for the taxing of leisure time aspect versus human capital/labor market frictions, we find support from men in Storstroem and women in Southern Jutland towards the leisure time aspect, and from men in Southern Jutland towards human capital accumulation/removal of labor market frictions.

\section{Conclusions}

This paper uses a randomized controlled trial of an early effort in labor market programs in Denmark to analyze distributional effects on post-unemployment earnings. The treatments were a job search assistance program, frequent meetings with a case worker, and faster entry into labor market training. We find that men react more to the early interventions in the short term than women and that Southern Jutland treated react more than Storstroem treated. We show that estimating average treatment effects cover over heterogeneous effects in the short term as there are clear heterogeneous impacts dependent on the earnings distribution. We find only limited evidence supporting that treatment have permanent impacts further than in the short term, however, when we do find medium and long term impacts, they seem to be associated with impacts on individuals with high earnings before entering unemployment whereas short term impacts that vanish are related to individuals with low earnings before entering unemployment. Of the different channels expected to 
have an impact on the effect of treatment, we thus find that the mere taxing of leisure time while unemployed seems to drive the results in three of four samples. We thus find that advancing the entry into active labor market programs have short term impacts on postunemployment labor market outcomes, but not necessarily medium or long term impacts. And since the effects predominantly comes by taxing of leisure time, they could probably have been delivered at a lower cost.

\section{REFERENCES}

Abbring, Jaap H. and Gerard J. van den Berg (2003), The Identifiability of the Mixed Proportional Hazards Competing Risks Model, Journal of the Royal Statistical Society Series B 65, no. Part 3:701-710.

Bitler, Marianne P., Jonah B. Gelbach, and Hillary W. Hoynes (2006), What Mean Impacts Miss: Distributional Effects of Welfare Reform Experiments, The American Economic Review 96, no. 4:988-1012.

(2008), Distributional Impacts of the Self-Sufficiency Project., Journal of Public Economics 92:748-765.

Black, Dan A., Jeffrey A. Smith, Mark C. Berger, and Brett J. Noel (2003), Is the Threat of Reemployment Services More Effective Than the Services Themselves? Evidence from Random Assignment in the UI System, American Economic Review 93, no. 4:1313-1327.

Blasco, Sylvie and Michael Rosholm (2011), The Impact of Active Labour Market Policy on Post-Unemployment Outcomes: Evidence from a Social Experiment in Denmark, iZA Discussion Paper No. 5631.

Card, David, Jochen Kluve, and Andrea Weber (2010), Active Labour Market Policy Evaluations: A Meta-Analysis, The Economic Journal 120, no. November:F452-F477.

_ (2015), What Works? A Meta Analysis of Recent Active Labor Market Policy Evaluations, NBER Working Paper No. 21431.

Cockx, Bart and Matteo Picchio (2013), Scarring Effects of Remaining Unemployed for Long-Term Unemployed School-Leavers, Journal of the Royal Statistical Society: Series A (Statistics in Society) 176, no. 4:951-980. 
Crepon, Bruno, Muriel Dejemeppe, and Marc Gurgand (2005), Counseling the Unemployed: Does it Lower Unemployment Duration and Recurrence?, IZA Discussion Paper No. 1796.

Dammert, Ana C. (2009), Heterogeneous Impacts of Conditional Cash Transfers: Evidence from Nicaragua, Economic Development and Cultural Change 59, no. 1:53-84.

Djebbari, Habiba and Jeffrey Smith (2008), Heterogenous Impacts in PROGRESA, Journal of Econometrics 145:64-80.

Dolton, Peter and Donal O'Neill (1996), Unemployment Duration and the Restart Effect: Some Experimental Evidence, The Economic Journal 106, no. 435:387-400.

Gaure, Simen, Knut Røed, and Lars Westlie (2012), Job Search Incentives and Job Match Quality, Labour Economics 19, no. 3:438-450.

Gautier, Pieter A., Paul Muller, Bas van der Klaauw, Michael Rosholm, and Michael Svarer (2012), Estimating Equilibrium Effects of Job Search Assistance, IZA Discussion Paper No. 6748.

Graversen, Brian and Jan C. van Ours (2008a), Activating Unemployed Workers Work: Experimental Evidence from Denmark, Economics Letters 100:308-310. (2008b), How to Help Unemployed Find Jobs Quickly: Evidence from a Mandatory Activation Programme, Journal of Public Economics 92:2020-2035.

Heckman, James J., Hidehiko Ichimura, and Petra E. Todd (1997a), Matching As An Econometric Evaluation Estimator: Evidence from Evaluating a Job Training Programme, The Review of Economic Studies 64:605-654.

Heckman, James J., Jeffrey Smith, and Nancy Clements (1997b), Making the Most Out of Programme Evaluations and Social Experiments: Accounting for Heterogeneity in Programme Impacts, The Review of Economic Studies 64, no. 4:487-535.

Jespersen, Svend T., Jakob R. Munch, and Lars Skipper (2008), Costs and Benefits of Danish Active Labour Market Programmes, Labour Economics 15:859-884.

Larsson, Laura (2003), Evaluation of Swedish Youth Labor Market Programs, The Journal of Human Resources 38, no. 4:891-927. 
Lechner, Michael (1999), Earnings and Employment Effects of Continuous Of-The-Job Training in East Germany after Unification, Journal of Business and Economic Statistics 17:74-90.

Munch, Jakob Roland and Lars Skipper (2008), Program Participation, Labor Force Dynamics, and Accepted Wage Rates, Advances in Econometrics 21:197-262.

Rosholm, Michael (2008), Experimental Evidence on the Nature of the Danish Employment Miracle, IZA Discussion Paper No. 3620.

Vikström, Johan, Michael Rosholm, and Michael Svarer (2013), The Relative Efficiency of Active Labour Market Policies: Evidence From a Social Experiment and NonParametric Methods, Labour Economics 24:58-67.

Vikström, Johan, Geert Ridder, and Martin Weidner (2015), Bounds on Treatment Effects on Transitions, the Institute for Fiscal Studies, Department of Economics, UCL, cemmap working paper CWP01/15. 


\section{Economics Working Papers}

2015-04: $\quad$ Sylvanus Kwaku Afesorgbor and Kaleb Girma Abreha: Preferential Market Access, Foreign Aid and Economic Development

2015-05: Ritwik Banerjee: Corruption, Norm Violation and Decay in Social Capital

2015-06: Christian Giødesen Lund and Rune Vejlin: Documenting and Improving the Hourly Wage Measure in the Danish IDA Database

2015-07: $\quad$ Anne Brink Nandrup: Do class size effects differ across grades?

2015-08: $\quad$ Mugdha Vaidya, Meghna Katoch and Nabanita Datta Gupta: The Impact of Household Participation in Community Based Organizations on Child Health and Education in Rural India

2015-09: $\quad$ Paola A. Barrientos Q., Niels-Hugo Blunch and Nabanita Datta Gupta: Income Convergence and the Flow out of Poverty in India, 1994-2005

2015-10: $\quad$ Peter S. Eppinger, Nicole Meythaler, Marc-Manuel Sindlinger and Marcel Smolka: The Great Trade Collapse and the Spanish Export Miracle: Firm-level Evidence from the Crisis

2015-11: $\quad$ Ella Paldam and Martin Paldam: The political economy of churches in Denmark over 700 years

2015-12: $\quad$ Ina C. Jäkel and Marcel Smolka: Trade Policy Preferences and the Factor Content of Trade

2015-13: Rene Saran and Norovsambuu Tumennasan: Implementation by Sortition in Nonexclusive Information Economies:

2015-14: $\quad$ Torben M. Andersen: The Greenlandic Economy - Structure and Prospects

2015-15: Jos Jansen: A Note on Quality Disclosure and Competition

2015-16: Martin Paldam: The rational economist in research: A model

2015-17: Kenneth Lykke Sørensen: Heterogeneous Impacts on Earnings from an Early Effort in Labor Market Programs 